\title{
Groundwater Potential Assessment and Characterization of Genale-Dawa River Basin
}

\author{
Nebiyou Kassahun', Mebruk Mohamed² \\ ${ }^{1}$ Hydraulic Engineering Department, Institute of Technology College, Debre Markos University, Debre Markos, Ethiopia \\ ${ }^{2}$ Civil and Environmental Engineering Department, Institute of Technology College, Addis Ababa University, \\ Addis Ababa, Ethiopia \\ Email: nebiyou_kassahun@dmu.edu.et, nebiyou.kassahun@yahoo.com, mebruk.mohammed@aait.edu.et
}

How to cite this paper: Kassahun, N. and Mohamed, M. (2018) Groundwater Potential Assessment and Characterization of Genale-Dawa River Basin. Open Journal of Modern Hydrology, 8, 126-144.

https://doi.org/10.4236/ojmh.2018.84010

Received: July 15, 2018

Accepted: October 26, 2018

Published: October 29, 2018

Copyright $\odot 2018$ by authors and Scientific Research Publishing Inc. This work is licensed under the Creative Commons Attribution International License (CC BY 4.0).

http://creativecommons.org/licenses/by/4.0/

\begin{abstract}
Genale-Dawa River Basin is one of the largest and most drought prone regions in Ethiopia. As a result a search for alternative source of water has always been a major issue in the region. This study therefore, aims at characterizing and evaluating the ground water potential resource of the river basin. The delineation and numerical discretization of the river basin were primarily done for the proper development of the problem domain. And the groundwater governing equation was solved at individual nodal points of the discretized region using a 3-D numerical ground water model called TAGSAC. This resulted in monthly average groundwater table fluctuation and replenishable ground water potential estimation. Hydrogeological classification was also done based on hydraulic conductivity values obtained from model calibration.
\end{abstract}

\section{Keywords \\ Ethiopia, Genale-Dawa River Basin, Numerical Groundwater Modeling, Replenishable Groundwater Potential, TAGSAC}

\section{Introduction}

Ethiopia, being one of the most hydrologically blessed countries in east Africa, is believed to have a large ground water potential reserve. Studies show erroneous results of $2.5 \mathrm{BCM}$ by WAPCOS, to $185 \mathrm{BCM}$ by Ayenew and Alemayehu, in 2001 [1], which can be taken as an indication of how much detailed study and survey is needed to estimate the countries resources with a better precision. This ambiguity in estimation can have a hindering effect on the countries pursuit to utilize its water resources potential to the limit.

The country's water supply coverage was estimated to be 30.9 percent, the ru- 
ral water supply coverage being 23.1 percent and that of urban being 74.4 percent [2]. Unpublished reports indicate that susceptibility to drought is higher in the periphery basins of the country such as Genale-Dawa than the central highlands due to high temporal variations of hydrological trends, making it hard to attain sustainable water supply in the region. Moreover, Master Plan Studies carried out during 1997-2007, indicates that Ethiopia has an estimated total potential irrigable land of $3,798,782$ ha out of which $1,074,720$ ha or $28.3 \%$ of the total irrigable land is in the Genale-Dawa River basin [3].

Ethiopia has suffered from repeated drought scenarios in the past; especially the peripheries of the country like Genale-Dawa basin are more prone to drought than the interior highlands. At driest seasons even major surface water sources dry up; as a result the available large areas of suitable irrigation land are left uncultivated and in times; standard domestic water supply become scarce. As a result proper management and utilization of water resource is vital in the region. In the past, studies have been done on the region to estimate the water resource potential. However, even though an estimation of groundwater resource was done based on different basic approaches in the region, basin wise groundwater numerical modeling has not been done, which is an effective approach to groundwater potential estimation and also reveals basic characteristics of the flow system. This can be of significant importance for the detailed understanding of available water resources and can contribute to the betterment of water resources planning and management. This study therefore attempts to produce a research output that can be useful for sustainable use of available groundwater resource.

Therefore, it can be drawn from the discussion above that, exploring sustainable and drought proof water resource is of significant importance. As an attempt to contribute to a suitable solution, this study focuses on evaluating the Genale-Dawa water resource potential and basic characterization of the ground water system. The study employs 3-D numerical ground water model to determine the monthly average groundwater table fluctuation and the replenishable groundwater potential of the basin which then is used to determine the amount of recharge/replenishable ground water potential. The result obtained is then combined with the result of groundwater potential result by base flow separation approach.

\section{Materials and Methodology}

\subsection{Data Collection}

Various relevant raw data that can reveal an insight of the subsurface reservoir and software useful for modeling were collected. These are:

Software used for the model development, including;

- Mat lab v.13a: where numerical calculations are carried out and the TAGSAC code is run.

- Global Mapper v.16, Surfer v.10: used for surveying works, delineation, digi- 
tization, data manipulation and data preprocessing.

Hydrogeological data

- 1:2000,000 resolution geological map with 56 geological classes were collected.

- Location and static water level of springs, Bore holes and hand dug wells.

- $30 \times 30$ m resolution Digital elevation model of the region in which Genale-Dawa River basin is located.

Hydrological data

- Rain fall data records of 23 gauging stations near and on the basin.

- Stream flow data of some gauging station on the basin; this was used to develop an understanding of the overall hydro geological system and also, determine aquifer contribution to the rivers by performing base flow separation.

\subsection{Numerical Solution Technique}

A particular type of FEM based three dimensional computer modeling code called TAGSAC (Three Dimensional Analysis of Groundwater Flow, Saitama University Code) is adopted for modeling the groundwater system. TAGSAC is a model developed for the porous medium. In the TAGSAC approximation procedure, the flow region is first discretized into a network of finite elements, and then trial approximating interpolation functions are generated for individual finite elements using a special type of weighted residual method called Galerkin's method; in which the summation of residuals weighted by interpolation functions is equated to zero. This results in a system of linear interpolation functions. By incorporating boundary conditions and solving, coefficients of interpolation functions are obtained. This system of equations is used to represent the unknown dependent variable (hydraulic head) over the discretized region. A limiting feature of TAGSAC model is that it is bound to use a model thickness not less than half the finite elements dimension used; which otherwise will risk numerical instability. TAGSAC has proved to be applicable in a number of researches done all over the globe [4].

\subsection{Spatial Discretization}

The geometric representation of the system shall first be established for which, Cartesian coordinate system is employed to generate a triangular in plane three dimensional mesh. The $x-y$ plane coincides with plane view of the study area where as $\mathrm{z}$ direction point's perpendicularly in the upward direction to the $\mathrm{x}-\mathrm{y}$ plane; representing elevation.

An initial step taken for discretization was to delineate the Genale-Dawa catchment area which was done using Global Mapper version 16 and using digital elevation model of $30 \times 30 \mathrm{~m}$ resolution. The result obtained was a little different than the official delineated map of Genale-Dawa river basin used by MOWE in that the delineation result obtained and to be used for this study has some additional area on the south-eastern part of the basin with a total of $17,860 \mathrm{~km}^{2}$. This, in recent master plan study of the basin was recognized. 
After the delineation $x-y$ coordinates of the catchment boundary are generated and used as problem domain of the model. The discretization elements are made to be non-uniform in size to best fit the boundaries of the problem domain where there are Sharpe corners. A maximum of $5 \mathrm{~km}$ edge dimension for the equilateral triangular finite element is selected. This is done considering the available computational capacity and level of details of raw data available. The problem domain of $17,860 \mathrm{~km}^{2}$ area is then discretized in to 9810 nodes of known $\mathrm{x}$-y coordinates with consistent and continuous nodal numbering assigned to them. 17,862 triangular elements are formed by connecting three neighboring nodes with a line. This geometric discretization of the region is first done on $x-y$ plane and is carried out using automatic discretizing Mat lab computer code. The $\mathrm{z}$ coordinate of the nodal points of the mesh is tabulated by interpolation from the digital elevation model. After wards this triangular mesh so formed is given a model thickness of $2500 \mathrm{~m}$ to form a three dimensionally discretized region. Hence, each triangular two dimensional element was changed in to three dimensional finite element formed with six nodal points in space and becomes a prism that is triangular in plain. Boreholes and springs are represented by 3 nearest surface nodes whereas River systems are made to traverse along a series of surface nodes; this is done by moving the nearest surface node to the river at a point using a mat lab code. Relocation of the top layer nodes near a river causes vertical distortion of the prismatic finite elements that can be handled by TAGSAC.

Finally, individual elements and surface nodal points are given codes that designate the material property and rainfall recharge amount respectively to the individual elements and surface nodes. Figure 1(a) and Figure 1(b) respectively show the delimited map and geometrically discretized domain.

Geological classes of the basin shown in Figure 2 have been obtained from National Ministry of Water Resources and Energy (MOWR) master plan study. These geological classes were used to define material properties of individual meshed elements of geological classes.

\subsection{Conceptual Model}

\subsubsection{Conceptualization of Flow Medium}

Several conceptual groundwater flow models have be distinguished on the basis

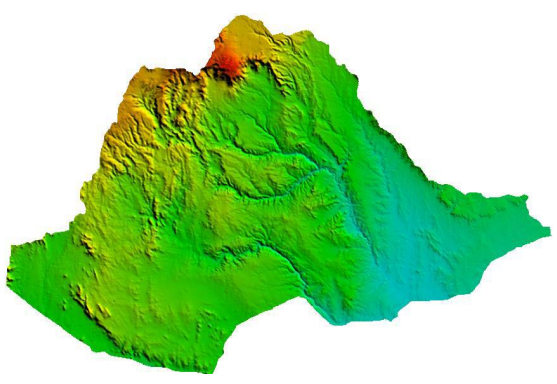

(a)

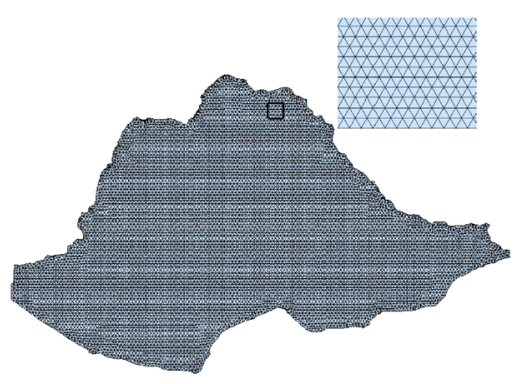

(b)

Figure 1. Delineated and discretized map of Genale-Dawa river basin. 


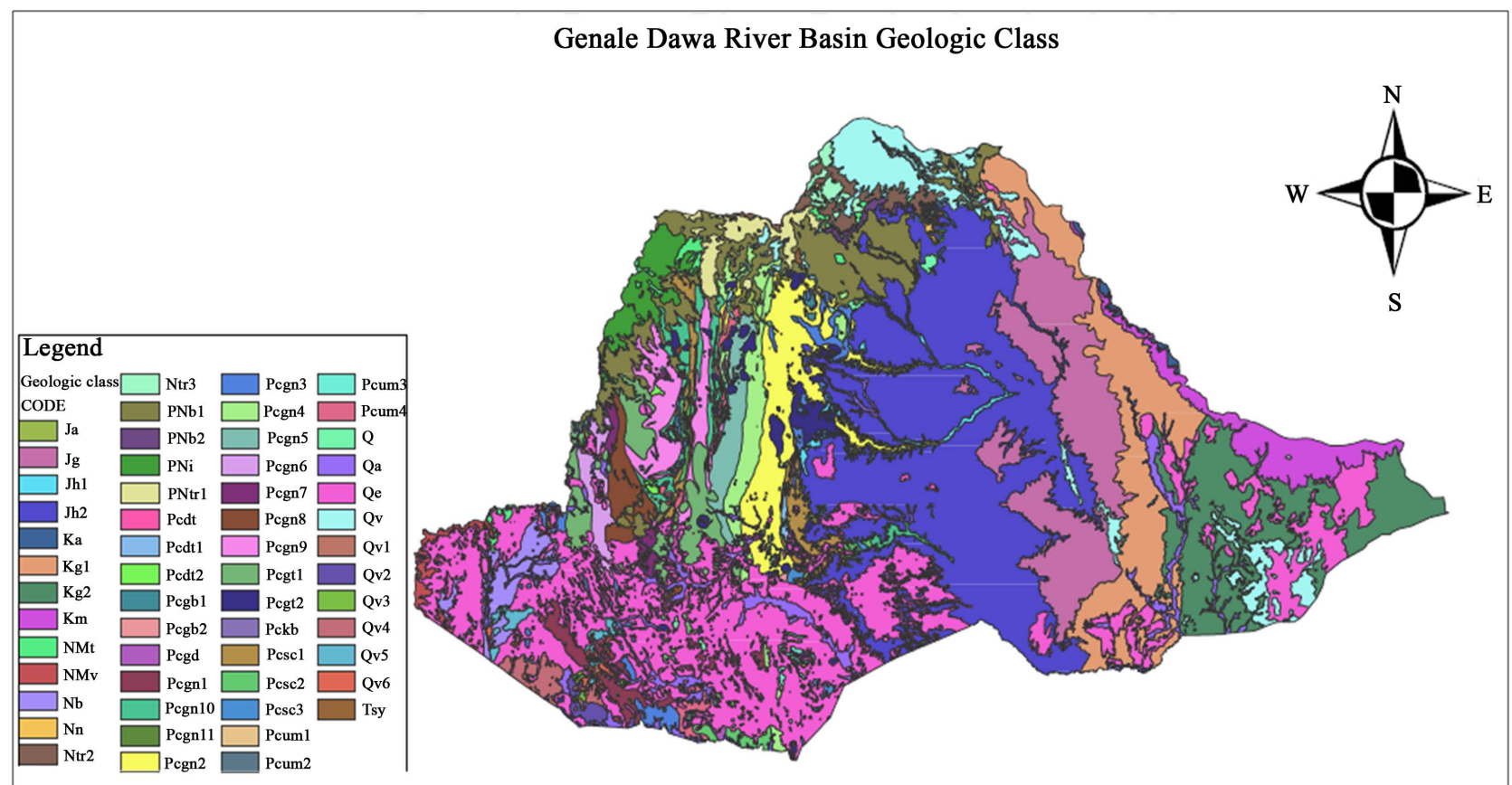

Figure 2. Geologic class of Genale-Dawa river basin (Source: MOWR, integrated river basin master plan studies).

of the storage and flow capabilities of the porous medium and fracture. Among these, dual continuum, discrete fracture network, and single equivalent continuum types are the major once. Considering the vastness of the area under study and the extensive computational requirements associated with it, this study has adopted the single equivalent continuum approach to represent the geologic medium in the region. This allows finer representative elements to be used capturing the very high specially divers geological composition of Genale-Dawa river basin [5].

Hydraulic properties important for the three dimensional conceptual model include both horizontal and vertical hydraulic conductivities as well as specific storage coefficients. The distribution of these parameters must be specified for each geological unit. However since the model is based on the principles of equivalent porous medium, Hydraulic properties are assumed to be equivalent or effective values in the vertical extent for the 56 individual geological class. These geological classes have been discretized and Equivalent hydraulic properties are set as calibration parameters for respective geological classes.

\subsubsection{Ground Water Recharge}

Recharge is defined as the downward flow of water reaching the water table forming an addition to the ground water reservoir [6]. Groundwater recharge rate is both specially and temporally varied [7]. This variability is due to a number of factors such as; climate, soil cover, geology, surface topography, hydrology and vegetation cover. Therefore, a good recharge estimation for a given study area; requires a clear understanding of the factors in play for the specific site under study. This usually, is not an easy task to achieve because of both financial 
and technical difficulties faced with. However, some methods such as Chemical tracer methods, Water-budget methods and numerical modeling methods in which Recharge estimates can be obtained through a model calibration process with recharge rate as a calibration parameter can be used to get a close estimation [7].

Major natural recharge to the aquifer system in the current study area is believed to occur at elevated regions due to percolation from the major precipitation areas along the north, north-eastern and north-western boundary highs of the basin. Whereas recharge from runoff and precipitation on the lower part of the basin also provides a source of groundwater inflow to the area of interest.

This study tries to estimate the replenishable groundwater resource (from hydrological perspective) using the TAGSAC model by seating precipitation to be some portion of the total rainfall in percent and making this percentage a calibration parameter that can be obtained through a series of trial and error procedure.

\subsubsection{Model Boundary Conditions}

It is crucial to define boundary conditions prior to numerical groundwater model development. This is because, the solution of Laplace's equation requires specification of boundary conditions which constrain the problem and make solutions unique [8]. The following boundary conditions have also been distinguished:

1) Head is known for surfaces bounding the flow region (Dirichlet Conditions);

2) Flow is known across surfaces bounding the region (Newman condition);

3) A combination of Dirichlet and Newman conditions known as mixed condition.

The most common types of boundary conditions are; perennial rivers, springs, lakes and swampy areas known to have ground water reserve underneath, all of which can be taken as Dirichlet boundary conditions. On the other hand; known amount of inter-aquifer leakage, water wells and springs of known discharge can be taken as Newman's conditions. The determination of which aspects of an actual ground-water system should be incorporated into a computer simulation usually depends, in part, upon the objectives of the study for which the model is being developed [9] accordingly constant head constant discharge and specified flow boundary conditions have been identified for the current modeling.

\subsubsection{Model Calibration and Evaluation}

In the model calibration, simulated heads and discharges are typically compared to their observed counterparts. If a model is well calibrated, there will be some random deviations between simulated and observed data, but there will not be systematic deviations. If there are systematic deviations such as most simulated heads exceeding observed heads, the calibration is poor and adjustments should be made [10]. These trial runs of the model are repeated until some kind of re- 
quired accuracy or calibration target is achieved [11]. When calibration is Saied to give an acceptable result; it is evaluated both qualitatively and quantitatively to assure the uniqueness of the solution.

1) Qualitatively, by comparison of contour maps of measured and computed parameters, which provides only a qualitative measure of the similarity between the patterns; and

2) Quantitatively, by a scatter plot of measured and computed parameters, where the deviation of points from the straight line should be randomly distributed [11]. In an effort to minimize the error in the calibration, the average deviation is calculated using the mean error (ME), mean absolute error (MAE) and root mean squared error (RMS) indicators, the calibration is continued until these indicators are satisfactorily minimized.

\subsubsection{Estimation of Groundwater Potential}

After the model calibration, monthly water table fluctuation is calculated. This helps determine the maximum water table, minimum water table and eventually the change in storage of the groundwater system within a year. This amount of water is known as the replenishable groundwater which represents the recharge capacity of the system. But, even though in a given month the aquifer is assumed to have a given amount of groundwater storage with an associated water table, it also discharges to the rivers at the same time. Hence, base flow separation is done using digital filter method to account for the water at the discharging end of the aquifer system and the cumulative groundwater reserve is calculated for individual months.

Finally based on calibration results hydraulic conductivities of different geologic classes are grouped to generate the different hydro-geologic classes of the region and prepare hydrogeologic map of the region.

\subsubsection{Model Protocol}

All the discussion made in this chapter applies to the numerical model development of Genale-Dawa River Basin. The model protocol followed and work frame adapted to modeling of the basin can be represented with a flow diagram as shown in Figure 3.

\section{Results and Discussion}

\subsection{Water Point Inventory Data}

Out of the collected Water point inventory data, some data was omitted for not qualifying to contain either the static water level or coordinate information. A secondary data screening was also done by comparing recorded static water level with expected result from the model. Accordingly, judgment was made to discard where large data inconsistency is observed. After screening 82 Bore holes, 49 hand dug wells and 191 spring data were left to be used as an input for the model. The distribution of water points used for model calibration is shown in Figure 4. From the distribution of this water points it can be seen that more 


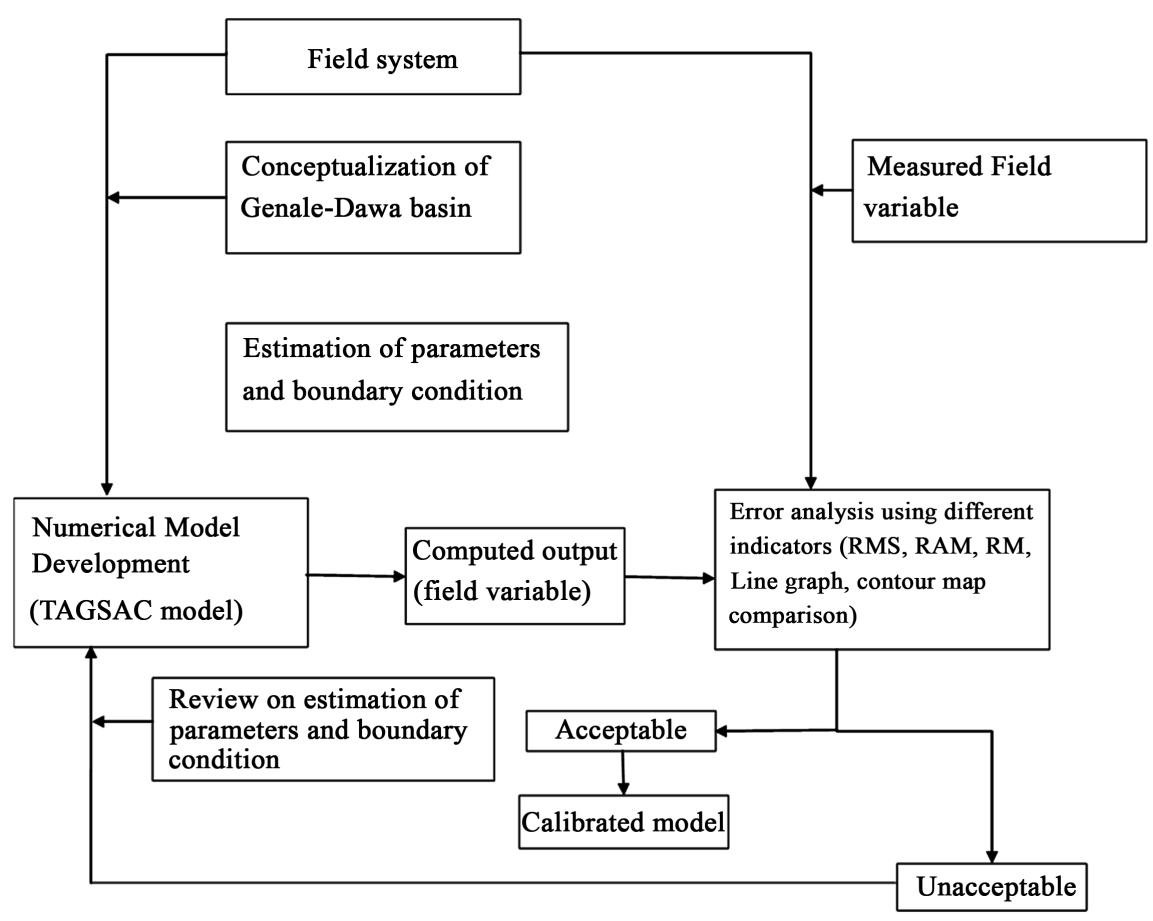

Figure 3. Flow diagram representation of model calibration protocol.

Water point distribution on Genale-Dawa river basin

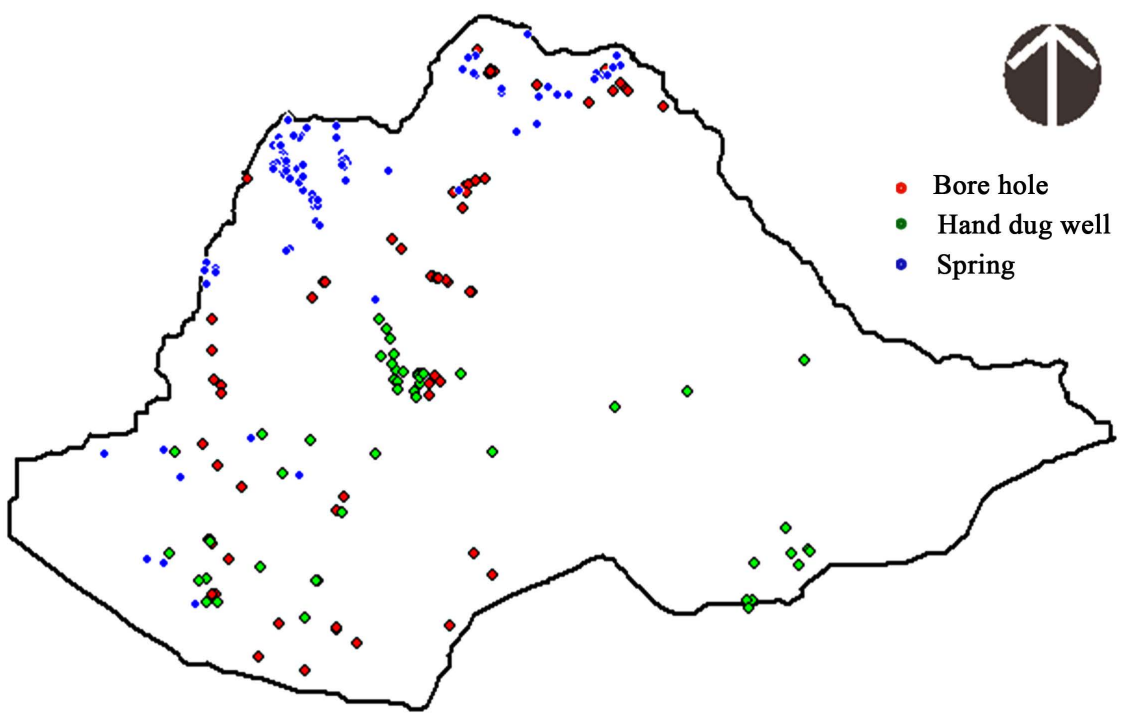

Figure 4. Water point distribution in Genale-Dawa river basin.

water points are located in the northern north-western and north-eastern parts of the basin which in general are topographically elevated areas. These parts of the basin are also the ones that receive majority of the precipitation and consequently expected to have majority of the recharge in the basin. On the other hand it can be seen that there is less concentration in the central and south-western parts of the basin. Therefore, even though there is uniformity absence in the distribution of water point for an ideal model calibration use, the 
fact that the distribution of water well data tends to be concentrated on parts of major recharging areas of the basin is fortunate and has a positive effect in capturing and conceptualizing the main features of the groundwater flow system for recharge potential estimation.

\subsection{Rainfall Distribution}

Determination of rainfall distribution over the basin is important prior to modeling in the groundwater potential assessment. It is used to approximate the amount of recharge from precipitation. Hence, Precipitation data of the study area was collected from Ethiopian National metrological Agency with a maximum of 15 years and a minimum of 10 years record. Data filling was done where there is missing. This was accomplished using a math lab program that uses the inverse distance method which was developed and coded by the authors of this study. The program is capable of dealing with a large amount of data; the Mat lab code of this program is attached in Appendix 4 for reference. After all fills were done; Point rainfall data is used to determine the spatial rainfall distribution over the entire basin. The Thiessen polygon generated for the Bore hole Hand dug well Spring Genale-Dawa River basin on the bases of 23 rain fall stations presented in Figure 5.

\subsection{Base Flow Separation}

Monthly stream flow data of 12 gauging stations over the basin was collected. The length of data record ranges from 15 to 20 yrs. prior to using these data for the determination of base flow contribution to rivers, quality check was done using outlier testing. And data filling was done using single and multiple regression techniques alternatively for different stations. The choice of using either one was depending on the hydrological similarity between the gauging stations. After all the necessary data check and fills were done, digital filter method was employed to perform base flow separation of different stations. the result is shown in Table 1 (Appendix).

Table 1. Monthly base flow contribution at gauging stations.

\begin{tabular}{|c|c|c|c|c|c|c|c|c|c|c|c|c|c|}
\hline \multirow{2}{*}{ Month } & \multicolumn{12}{|c|}{ Station Name } & \multirow{2}{*}{$\begin{array}{l}\text { Monthly } \\
\text { Total }\left(\mathrm{M}^{3}\right)\end{array}$} \\
\hline & Yadot & Welemel & Wyib & Togona & Mormora & Mesol & Mana & Healgo & Genale & Awata & Dimtu & Deyou & \\
\hline Jan & 4.05 & 11.73 & 1.29 & 0.89 & 9.19 & 2.04 & 0.08 & 0.65 & 42.75 & 8.36 & 0.02 & 10.38 & 2742.50 \\
\hline Feb & 3.01 & 9.20 & 1.60 & 0.47 & 6.52 & 1.55 & 0.08 & 0.55 & 44.14 & 10.21 & 0.01 & 11.15 & 2654.48 \\
\hline Mar & 4.38 & 10.27 & 2.71 & 0.33 & 7.21 & 1.51 & 0.10 & 0.59 & 57.14 & 10.38 & 0.04 & 11.86 & 3195.32 \\
\hline Apr & 5.47 & 14.51 & 3.13 & 0.45 & 10.33 & 1.96 & 0.23 & 0.80 & 84.17 & 11.15 & 0.05 & 12.75 & 4350.28 \\
\hline May & 5.89 & 16.30 & 2.40 & 1.08 & 12.73 & 2.21 & 0.27 & 0.92 & 138.18 & 11.86 & 0.06 & 14.25 & 6184.58 \\
\hline Jun & 6.02 & 16.56 & 4.16 & 1.26 & 12.71 & 2.29 & 0.29 & 0.82 & 124.97 & 12.75 & 0.09 & 14.77 & 5900.45 \\
\hline Jul & 6.31 & 18.17 & 45.49 & 1.15 & 13.48 & 2.49 & 3.64 & 9.32 & 157.15 & 14.25 & 0.69 & 11.74 & 8516.10 \\
\hline Aug & 6.63 & 19.49 & 6.13 & 16.31 & 14.09 & 30.51 & 0.45 & 0.72 & 206.51 & 14.77 & 0.06 & 6.74 & 9672.67 \\
\hline Sep & 6.94 & 214.22 & 6.65 & 1.84 & 14.76 & 2.79 & 0.46 & 0.65 & 211.70 & 11.74 & 0.07 & 4.49 & 14289.19 \\
\hline Oct & 76.75 & 22.23 & 4.00 & 2.11 & 162.57 & 3.00 & 0.48 & 0.74 & 247.42 & 6.74 & 0.08 & 4.17 & 15909.17 \\
\hline Nov & 7.87 & 22.66 & 2.43 & 2.29 & 17.18 & 3.11 & 0.34 & 0.79 & 826.60 & 4.49 & 0.09 & 8.18 & 26881.03 \\
\hline Dec & 6.32 & 16.85 & 1.25 & 1.72 & 14.33 & 2.87 & 0.17 & 0.69 & 811.52 & 4.17 & 0.04 & 9.83 & 26092.85 \\
\hline
\end{tabular}




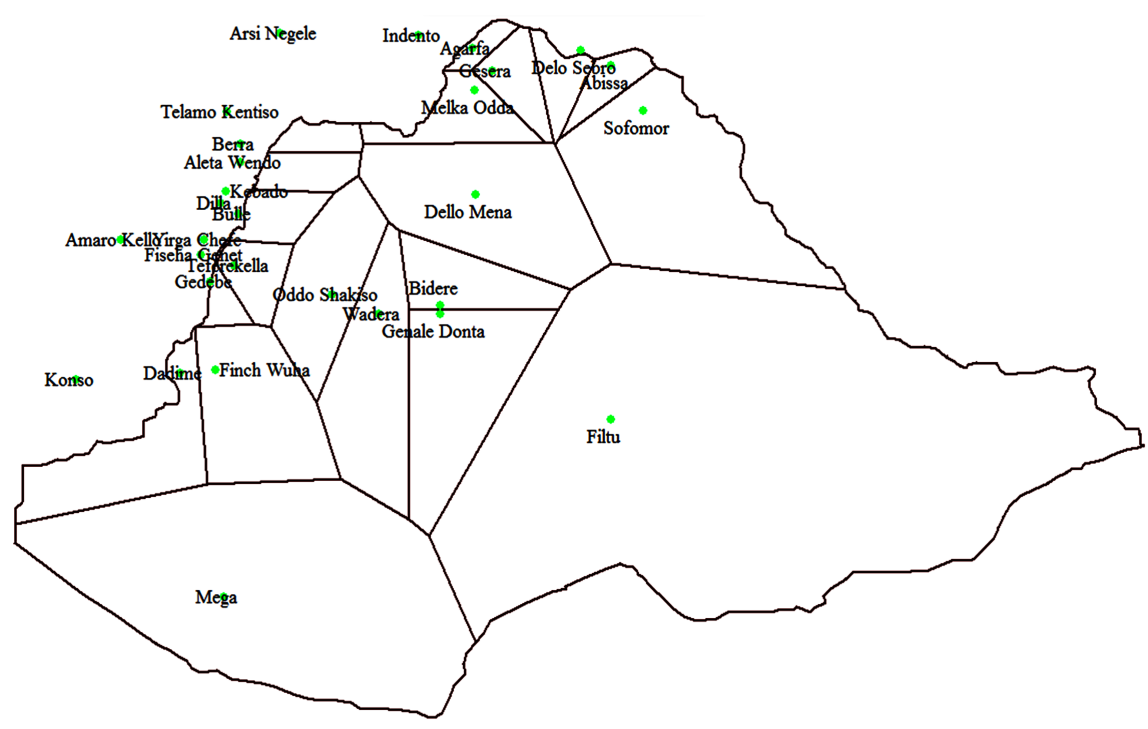

Figure 5. Thiessen polygon diagram generated on Genale-Dawa river Basin.

\subsection{Flow System Boundary}

Rivers as previously discussed are represented in the model with a set of nodal points that collectively make up the river system. Sections of rivers that cut through an aquifer to a considerable length have been identified in the region, they are considered as gaining rivers and in hydrological terms they are named Perennial Rivers; ones that do not dry throughout the season of the year. Some sections of the rivers that displayed such characteristics include Genale, Dawa, Gestro, Mena Weyeb and others small streams as well. These rivers, since they are gaining and are exposed to atmospheric pressure, can be taken as constant head boundaries (Dirichlet condition). Hence, the set of nodes that represent these rivers are set to have known hydraulic head equivalent to atmospheric head.

On the other hand, river sections that lose water to an aquifer are named losing or intermittent rivers. These types of rivers recharge the ground water with a loss rate that is variable spatially and temporally. They can be taken as specified flow boundary if the loss or gain rate of the stream is known spatially and temporally [8]. However, this recharge rate is difficult to determine explicitly. Nevertheless, considering recharge to an aquifer ultimately results from rain fall; recharge from losing rivers in this study area is implicitly represented with rate of recharge by precipitation.

Moreover, the peripheral physical boundaries of the discretized region lie mostly on topographic highs locking the river basin, the regional groundwater divides are also assumed to align to these topographic conditions. Hence, it is assumed that the boundaries of the basin are no flow boundaries. In addition, the bottom surface of the region which in this study is taken to be $2500 \mathrm{~km}$ deep is assumed to have an impermeable bed making it a no flow boundary. At the same time, considering recharge due to precipitation is a major source to 
groundwater in the basin, this study also takes recharge rate into ground-water as a specified flow boundary condition along the top boundary of the groundwater model. The conceptual boundary conditions are presented in Figure 6.

\subsection{Model Calibration}

After conceptualization of the flow system was complete and numerical model developed, TAGSAC model calibration was done by successively seating trial hydraulic conductivity values for individual geological classes until acceptable match was made between the historical hydraulic head record and simulated hydraulic head values. The resulting match was evaluated quantitatively using average indicators (AM, RMS, MAE) and qualitatively by comparison of groundwater contour maps generated with recorded and simulated hydraulic head data.

(A) Quantitative Check

1) The mean error (ME)

$$
\mathrm{ME}=\frac{1}{n} \sum_{i=1}^{n}\left(h_{\text {measured }}-h_{\text {computed }}\right)_{i}=3.91
$$

2) The mean absolute error (MAE)

$$
\text { AME }=\frac{1}{n} \sum_{i=1}^{n}\left|\left(h_{\text {measured }}-h_{\text {computed }}\right)_{i}\right|=7.46
$$

3) The root mean squared error (RMS)

$$
\mathrm{RMS}=\sqrt{\frac{1}{n} \sum_{i=1}^{n}\left(h_{\text {measured }}-h_{\text {computed }}\right)_{i}^{2}}=10.65
$$

\section{(B) Qualitative check}

From the qualitative comparison result presented by Figure 7, the contour lines generated based on simulated and recorded data seem to agree well. The resemblance between the two contour maps is an indication of how well the

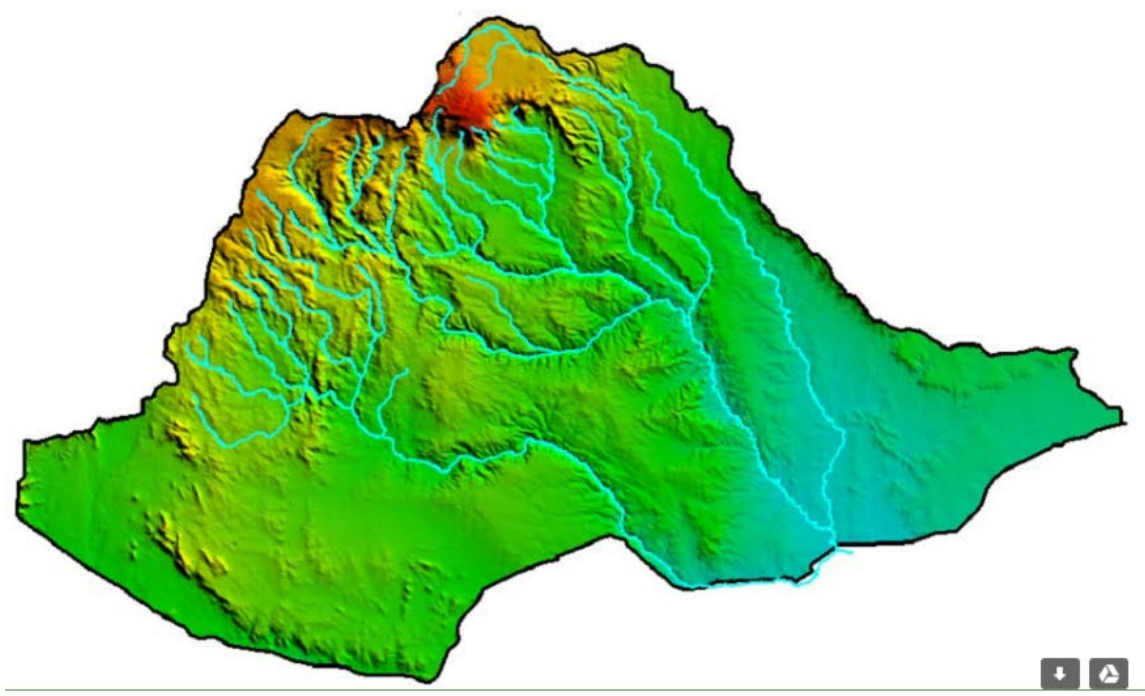

Figure 6. Flow system boundaries of numerical model. 

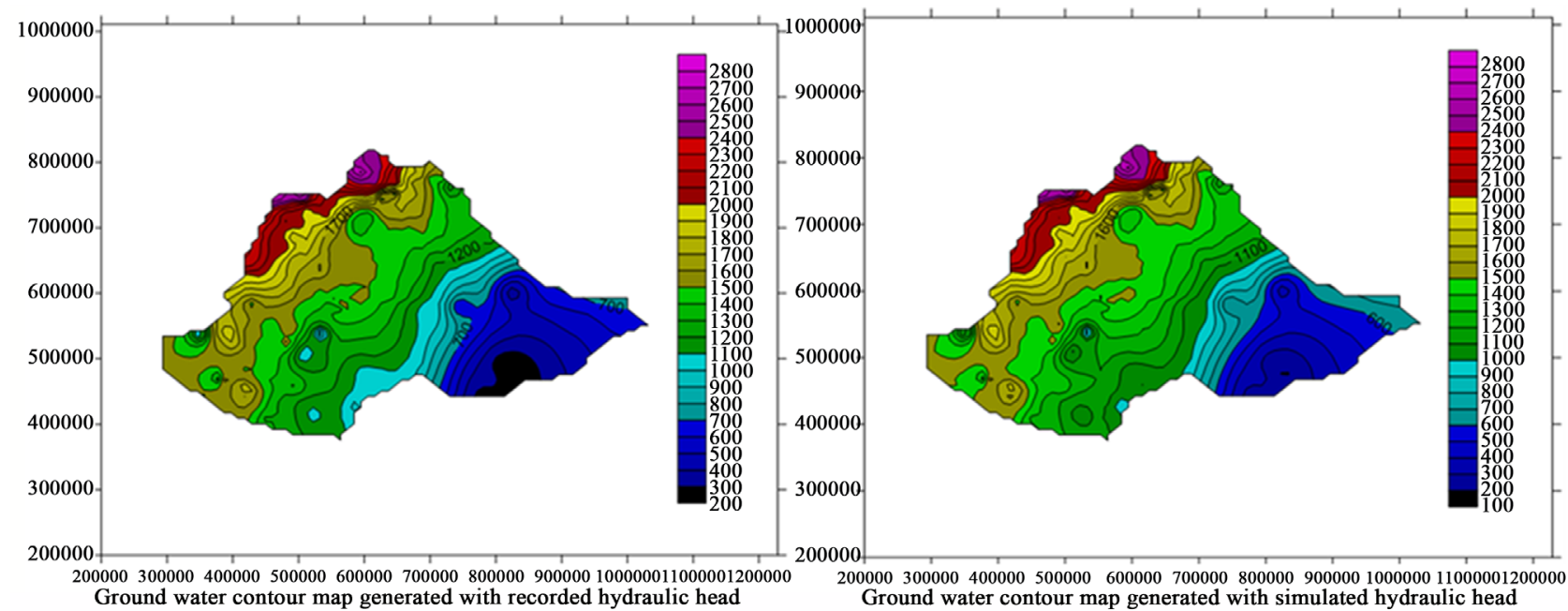

Figure 7. Qualitative check by compering contour maps of recorded and simulated water table.

model is calibrated and that the model represents the real system. Even though complete similarity is unachievable, a faire resemblance seems to exist. Considering the resolution of modeling and quality of data used, this result has been taken acceptable. The resulting horizontal and vertical hydraulic conductivity distribution for individual geologic classes are presented in Table 2.

Groundwater table (piezometric head) of the region is calculated for each month in a year; using the calibrated model at nodal points. Afterwards conditions of possible maximum and possible minimum porosities of individual geologic mediums are taken. For each of these two conditions, monthly storage calculations in individual finite elements are done. The average of these tow conditions is used to determine groundwater table configuration in each month. This monthly groundwater table location showed seasonal fluctuation of the water table as shown in Figure 8. Thereafter, the determination of replenishable groundwater potential of the region is done by quantifying the amount of water that is only temporarily stored in the ground and drains to rivers, springs and lost due to evapotranspiration at latter times. Therefore minimum water table in the seasonal fluctuation is taken as benchmark for zero replenishable ground water storage.

The Ground water fluctuation trend seems to be comparable with rainfall series of the region for the most part, but near the 9th month it showed erratic behavior. This could be a cumulative result of a very complex geologic composition of the region and spatially non uniform rainfall pattern in the region.

In order to determine the total replenishable ground water reserve, monthly contribution of groundwater to rivers shall also be taken in to account. Accordingly base flow separation of stream flow data was done using single parameter digital filter approach (Appendix 1) and the result was added to the volume of replenishable ground water obtained from the model. This has resulted in 2.78 BM3 as total replenishable groundwater in Genale Dawa basin; the result is shown in Table 3. 
Table 2. Hydraulic conductivity values of different geologic medium on Genale-Dawa river basin (Geologic coding is presented in Appendix and is consistent with Figure 2).

\begin{tabular}{|c|c|c|c|c|}
\hline \multirow{2}{*}{ Geologic class code } & \multicolumn{4}{|c|}{ Hydraulic Conductivity } \\
\hline & $\mathrm{Kx}(\mathrm{m} / \mathrm{s})$ & $\mathrm{Ky}(\mathrm{m} / \mathrm{s})$ & $\mathrm{Kz}(\mathrm{m} / \mathrm{s})$ & Keq \\
\hline $\mathrm{Ja}$ & $8.64 \mathrm{E}-05$ & $8.64 \mathrm{E}-05$ & $8.64 \mathrm{E}-05$ & $8.03 \mathrm{E}-07$ \\
\hline Jg & $1.30 \mathrm{E}-05$ & $1.30 \mathrm{E}-05$ & $8.64 \mathrm{E}-05$ & $1.20 \mathrm{E}-07$ \\
\hline Jh1 & $8.64 \mathrm{E}-05$ & $8.64 \mathrm{E}-05$ & $8.64 \mathrm{E}-05$ & $8.03 \mathrm{E}-07$ \\
\hline Jh2 & $1.73 \mathrm{E}-05$ & $1.73 \mathrm{E}-05$ & $2.16 \mathrm{E}-04$ & $2.54 \mathrm{E}-07$ \\
\hline $\mathrm{Ka}$ & $8.64 \mathrm{E}-05$ & $8.64 \mathrm{E}-05$ & $8.64 \mathrm{E}-05$ & $8.03 \mathrm{E}-07$ \\
\hline $\operatorname{kg} 1$ & $8.64 \mathrm{E}-05$ & $8.64 \mathrm{E}-06$ & $2.16 \mathrm{E}-04$ & $4.02 \mathrm{E}-07$ \\
\hline kg2 & $7.78 \mathrm{E}-04$ & $7.78 \mathrm{E}-04$ & $8.56 \mathrm{E}-04$ & $2.28 \mathrm{E}-05$ \\
\hline $\mathrm{Km}$ & $8.64 \mathrm{E}-05$ & $8.64 \mathrm{E}-05$ & $8.64 \mathrm{E}-05$ & $8.03 \mathrm{E}-07$ \\
\hline $\mathrm{Nb}$ & $8.64 \mathrm{E}-04$ & $8.64 \mathrm{E}-04$ & $8.64 \mathrm{E}-05$ & $8.03 \mathrm{E}-06$ \\
\hline NMt & $8.64 \mathrm{E}-04$ & $8.64 \mathrm{E}-05$ & $8.64 \mathrm{E}-05$ & $2.54 \mathrm{E}-06$ \\
\hline $\mathrm{NMv}$ & $8.64 \mathrm{E}-04$ & $8.64 \mathrm{E}-05$ & $1.73 \mathrm{E}-04$ & $3.59 \mathrm{E}-06$ \\
\hline $\mathrm{Nn}$ & $8.64 \mathrm{E}-04$ & $8.64 \mathrm{E}-05$ & $1.73 \mathrm{E}-04$ & $3.59 \mathrm{E}-06$ \\
\hline Ntr2 & $8.64 \mathrm{E}-04$ & $8.64 \mathrm{E}-05$ & $8.64 \mathrm{E}-05$ & $2.54 \mathrm{E}-06$ \\
\hline Ntr3 & $8.64 \mathrm{E}-05$ & $8.64 \mathrm{E}-05$ & $8.64 \mathrm{E}-05$ & $8.03 \mathrm{E}-07$ \\
\hline Pcdt & $8.64 \mathrm{E}-05$ & $8.64 \mathrm{E}-05$ & $8.64 \mathrm{E}-05$ & $8.03 \mathrm{E}-07$ \\
\hline Pcdt1 & $8.64 \mathrm{E}-05$ & $8.64 \mathrm{E}-05$ & $8.64 \mathrm{E}-05$ & $8.03 \mathrm{E}-07$ \\
\hline Pcdt2 & $8.64 \mathrm{E}-05$ & $8.64 \mathrm{E}-05$ & $8.64 \mathrm{E}-05$ & $8.03 \mathrm{E}-07$ \\
\hline Pcgb1 & $5.18 \mathrm{E}-04$ & $5.18 \mathrm{E}-05$ & $1.30 \mathrm{E}-04$ & $1.87 \mathrm{E}-06$ \\
\hline Pcgb2 & $8.64 \mathrm{E}-05$ & $8.64 \mathrm{E}-05$ & $8.64 \mathrm{E}-05$ & $8.03 \mathrm{E}-07$ \\
\hline Pcgd & $8.64 \mathrm{E}-05$ & $8.64 \mathrm{E}-05$ & $8.64 \mathrm{E}-05$ & $8.03 \mathrm{E}-07$ \\
\hline Pcgn1 & $8.64 \mathrm{E}-08$ & $8.64 \mathrm{E}-08$ & $8.64 \mathrm{E}-08$ & $2.54 \mathrm{E}-11$ \\
\hline Pcgn2 & $8.64 \mathrm{E}-08$ & $8.64 \mathrm{E}-08$ & $4.32 \mathrm{E}-07$ & $5.68 \mathrm{E}-11$ \\
\hline Pcgn3 & $8.64 \mathrm{E}-08$ & $8.64 \mathrm{E}-08$ & $8.64 \mathrm{E}-08$ & $2.54 \mathrm{E}-11$ \\
\hline Pcgn4 & $8.64 \mathrm{E}-08$ & $8.64 \mathrm{E}-08$ & $8.64 \mathrm{E}-08$ & $2.54 \mathrm{E}-11$ \\
\hline Pcgn5 & $1.73 \mathrm{E}-07$ & $2.33 \mathrm{E}-06$ & $1.73 \mathrm{E}-08$ & $8.35 \mathrm{E}-11$ \\
\hline Pcgn6 & $8.64 \mathrm{E}-07$ & $8.64 \mathrm{E}-09$ & $8.64 \mathrm{E}-07$ & $8.03 \mathrm{E}-11$ \\
\hline Pcgn7 & $8.64 \mathrm{E}-07$ & $8.64 \mathrm{E}-07$ & $8.64 \mathrm{E}-08$ & $2.54 \mathrm{E}-10$ \\
\hline Pcgn8 & $8.64 \mathrm{E}-07$ & $7.78 \mathrm{E}-05$ & $4.32 \mathrm{E}-04$ & $1.70 \mathrm{E}-07$ \\
\hline Pcgn9 & $4.32 \mathrm{E}-06$ & $7.78 \mathrm{E}-07$ & $8.64 \mathrm{E}-07$ & $1.70 \mathrm{E}-09$ \\
\hline Pcgn10 & $8.64 \mathrm{E}-07$ & $8.64 \mathrm{E}-07$ & $2.16 \mathrm{E}-06$ & $1.27 \mathrm{E}-09$ \\
\hline Pcgn11 & $8.73 \mathrm{E}-07$ & $1.30 \mathrm{E}-06$ & $8.73 \mathrm{E}-07$ & $9.94 \mathrm{E}-10$ \\
\hline Pcgt1 & $4.75 \mathrm{E}-08$ & $4.75 \mathrm{E}-08$ & $8.64 \mathrm{E}-08$ & $1.40 \mathrm{E}-11$ \\
\hline Pcgt2 & $4.32 \mathrm{E}-07$ & $4.32 \mathrm{E}-07$ & $2.16 \mathrm{E}-07$ & $2.01 \mathrm{E}-10$ \\
\hline Pckb & $8.64 \mathrm{E}-07$ & $8.64 \mathrm{E}-08$ & $8.64 \mathrm{E}-08$ & $8.03 E-11$ \\
\hline Pcs1 & $8.64 \mathrm{E}-08$ & $8.64 \mathrm{E}-08$ & $8.64 \mathrm{E}-08$ & $2.54 \mathrm{E}-11$ \\
\hline
\end{tabular}




\section{Continued}

\begin{tabular}{|c|c|c|c|c|}
\hline Pcs2 & $8.64 \mathrm{E}-08$ & $8.64 \mathrm{E}-07$ & $2.16 \mathrm{E}-07$ & $1.27 \mathrm{E}-10$ \\
\hline Pcs3 & $8.64 \mathrm{E}-07$ & $8.64 \mathrm{E}-07$ & $8.64 \mathrm{E}-07$ & $8.03 \mathrm{E}-10$ \\
\hline Pcum1 & $8.64 \mathrm{E}-08$ & $8.64 \mathrm{E}-08$ & $8.64 \mathrm{E}-08$ & $2.54 \mathrm{E}-11$ \\
\hline Pcum2 & $8.64 \mathrm{E}-08$ & $4.32 \mathrm{E}-07$ & $8.64 \mathrm{E}-08$ & $5.68 \mathrm{E}-11$ \\
\hline Pcum3 & $8.64 \mathrm{E}-08$ & $8.64 \mathrm{E}-07$ & $8.64 \mathrm{E}-08$ & $8.03 \mathrm{E}-11$ \\
\hline Pcum4 & $8.64 \mathrm{E}-08$ & $8.64 \mathrm{E}-08$ & $8.64 \mathrm{E}-07$ & $8.03 \mathrm{E}-11$ \\
\hline PNb1 & $1.73 \mathrm{E}-04$ & $1.73 \mathrm{E}-05$ & $1.73 \mathrm{E}-05$ & $2.27 \mathrm{E}-07$ \\
\hline $\mathrm{PNb} 2$ & $8.64 \mathrm{E}-05$ & $8.64 \mathrm{E}-05$ & $8.64 \mathrm{E}-05$ & $8.03 \mathrm{E}-07$ \\
\hline $\mathrm{PNi}$ & $8.64 \mathrm{E}-05$ & $1.30 \mathrm{E}-04$ & $1.30 \mathrm{E}-04$ & $1.20 \mathrm{E}-06$ \\
\hline PNtr1 & $8.64 \mathrm{E}-08$ & $8.64 \mathrm{E}-08$ & $8.64 \mathrm{E}-07$ & $8.03 \mathrm{E}-11$ \\
\hline Q & $2.16 \mathrm{E}-03$ & $2.16 \mathrm{E}-03$ & $2.16 \mathrm{E}-03$ & $1.00 \mathrm{E}-04$ \\
\hline Q6 & $8.64 \mathrm{E}-05$ & $8.64 \mathrm{E}-05$ & $8.64 \mathrm{E}-05$ & $8.03 \mathrm{E}-07$ \\
\hline $\mathrm{Qa}$ & $4.34 \mathrm{E}-03$ & $4.34 \mathrm{E}-03$ & $4.34 \mathrm{E}-03$ & $2.86 \mathrm{E}-04$ \\
\hline Qe & $1.30 \mathrm{E}-06$ & $1.73 \mathrm{E}-06$ & $1.73 \mathrm{E}-05$ & $6.22 \mathrm{E}-09$ \\
\hline Qv & $4.34 \mathrm{E}-04$ & $4.34 \mathrm{E}-04$ & $4.34 \mathrm{E}-04$ & $9.03 \mathrm{E}-06$ \\
\hline Qv1 & $1.73 \mathrm{E}-04$ & $1.73 \mathrm{E}-03$ & $2.16 \mathrm{E}-03$ & $2.54 \mathrm{E}-05$ \\
\hline Qv2 & $8.64 \mathrm{E}-05$ & $8.64 \mathrm{E}-06$ & $8.64 \mathrm{E}-05$ & $2.54 \mathrm{E}-07$ \\
\hline Qv3 & $8.64 \mathrm{E}-05$ & $8.64 \mathrm{E}-05$ & $8.64 \mathrm{E}-05$ & $8.03 \mathrm{E}-07$ \\
\hline Qv4 & $8.64 \mathrm{E}-05$ & $8.64 \mathrm{E}-05$ & $2.16 \mathrm{E}-05$ & $4.02 \mathrm{E}-07$ \\
\hline Qv5 & $8.64 \mathrm{E}-05$ & $8.64 \mathrm{E}-05$ & $8.64 \mathrm{E}-05$ & $8.03 \mathrm{E}-07$ \\
\hline Tsy & $1.30 \mathrm{E}-04$ & $8.64 \mathrm{E}-04$ & $1.30 \mathrm{E}-04$ & $3.81 \mathrm{E}-06$ \\
\hline
\end{tabular}

Table 3. Total replenishable ground water calculation.

\begin{tabular}{cccc}
\hline Month & $\begin{array}{c}\text { Replenishable } \\
\text { Ground Water }\left(\mathbf{M}^{3}\right)\end{array}$ & $\begin{array}{c}\text { Base Flow Contribution } \\
\text { to Rivers }\left(\mathbf{M}^{3}\right)\end{array}$ & $\begin{array}{c}\text { Total Monthly Replenishable } \\
\text { Ground Water }\left(\mathbf{M}^{3}\right)\end{array}$ \\
\hline Jan & $1.05 \mathrm{E}+08$ & $2.74 \mathrm{E}+03$ & $1.05 \mathrm{E}+08$ \\
Feb & $3.03 \mathrm{E}+08$ & $2.65 \mathrm{E}+03$ & $3.03 \mathrm{E}+08$ \\
Mar & $3.79 \mathrm{E}+08$ & $3.20 \mathrm{E}+03$ & $3.79 \mathrm{E}+08$ \\
Apr & $4.11 \mathrm{E}+08$ & $4.35 \mathrm{E}+03$ & $4.11 \mathrm{E}+08$ \\
May & $2.65 \mathrm{E}+08$ & $6.18 \mathrm{E}+03$ & $2.65 \mathrm{E}+08$ \\
Jun & $1.02 \mathrm{E}+08$ & $5.90 \mathrm{E}+03$ & $1.02 \mathrm{E}+08$ \\
Jul & $0.00 \mathrm{E}+00$ & $8.52 \mathrm{E}+03$ & $8.52 \mathrm{E}+03$ \\
Aug & $2.63 \mathrm{E}+08$ & $9.67 \mathrm{E}+03$ & $2.63 \mathrm{E}+08$ \\
Sep & $1.63 \mathrm{E}+08$ & $1.43 \mathrm{E}+04$ & $1.63 \mathrm{E}+08$ \\
Oct & $2.54 \mathrm{E}+08$ & $1.59 \mathrm{E}+04$ & $2.54 \mathrm{E}+08$ \\
Nov & $2.65 \mathrm{E}+08$ & $2.69 \mathrm{E}+04$ & $2.65 \mathrm{E}+08$ \\
Dec & $2.64 \mathrm{E}+08$ & $2.61 \mathrm{E}+04$ & $2.64 \mathrm{E}+08$ \\
& Total Replenishable Ground Water & $2.78 \mathrm{E}+09$ \\
\hline
\end{tabular}




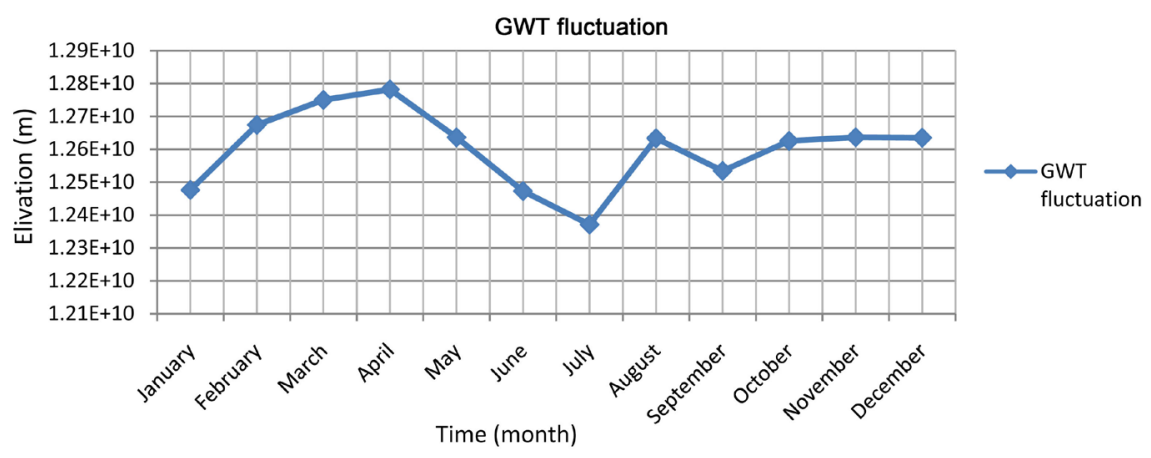

Figure 8. Mean monthly water table fluctuation.

\subsection{Hydrogeology of Genale-Dawa Basin}

From the hydraulic conductivity values obtained from calibration it can be seen that many geological formations have similar hydraulic properties, for instance geologic mediums (Pcgn, Pcgn3, Pcgn4, Pcs1, Pcum1and Ja, Jh1, ka, km, Ntr3, Pcdt, Pcdt1, Pcdt2, Pcgb2, Pcgd, PNb2, Q6, Qv3, Qv5) have the same equivalent hydraulic conductivities where as others if not the same they have close similarity. Geologic characteristics of the Genale-Dawa River Basin can therefore be better understood if geologic mediums with similar hydraulic conductivity are grouped together. Accordingly, the following groups have been made and presented in Figure 9.

- High hydraulic conductivity geologic medium $\left(>1 \times 10^{-4} \mathrm{~m} / \mathrm{s}\right)$;

- Moderately high hydraulic conductivity geologic medium $\left(1 \times 10^{-4}\right.$ to $1 \times 10^{-5}$ $\mathrm{m} / \mathrm{s}$ );

- Moderately low hydraulic conductivity geologic medium $\left(1 \times 10^{-4}\right.$ to $1 \times 10^{-7}$ $\mathrm{m} / \mathrm{s})$;

- Low hydraulic conductivity geologic medium $\left(1 \times 10^{-7}\right.$ to $\left.1 \times 10^{-12} \mathrm{~m} / \mathrm{s}\right)$.

Additionally, by looking at the velocity field distribution it is possible to identify major recharging and discharging areas shown in Figure 10. Circles in read show areas of recharge with dispersing velocity vectors, whereas circles in green show areas of discharge with collecting velocity vectors. But it should be noted that identified recharging sites can also be acting as discharging areas at the same time and vice versa. This can be witnessed if we look at the recharging areas at the northern part of the basin; all the velocity vectors are in dispersing position showing a major recharge taking place but at the same time perennial rivers emanate from those areas showing that it is also acting as a discharging site. Moreover it is seen that discharging sites do coincide with river networks showing points at which ground water contributes to rivers. But at points where recharging site is away from rivers, it is possibly an indication that the aquifer is discharging to an underlying strata.

\section{Conclusion and Recommendation}

\subsection{Conclusion}

Groundwater modeling has versatile applications in groundwater resources 


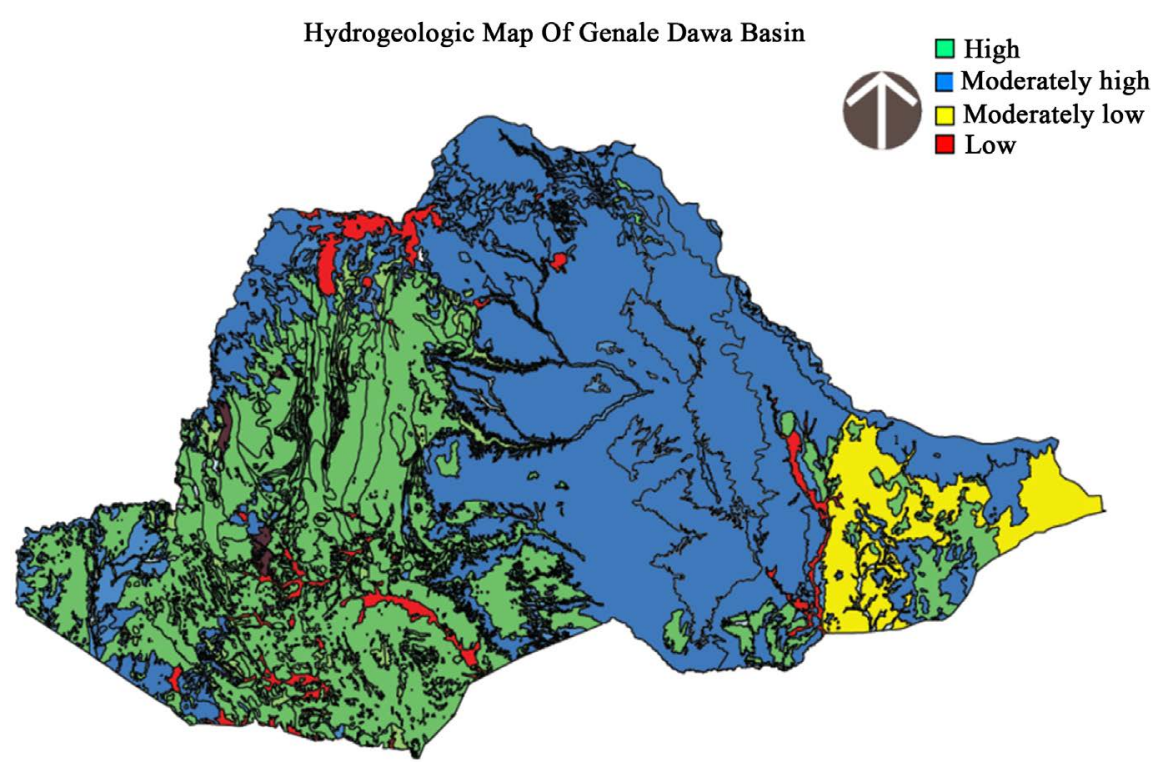

Figure 9. Hydrogeological map of Genale-Dawa river basin.

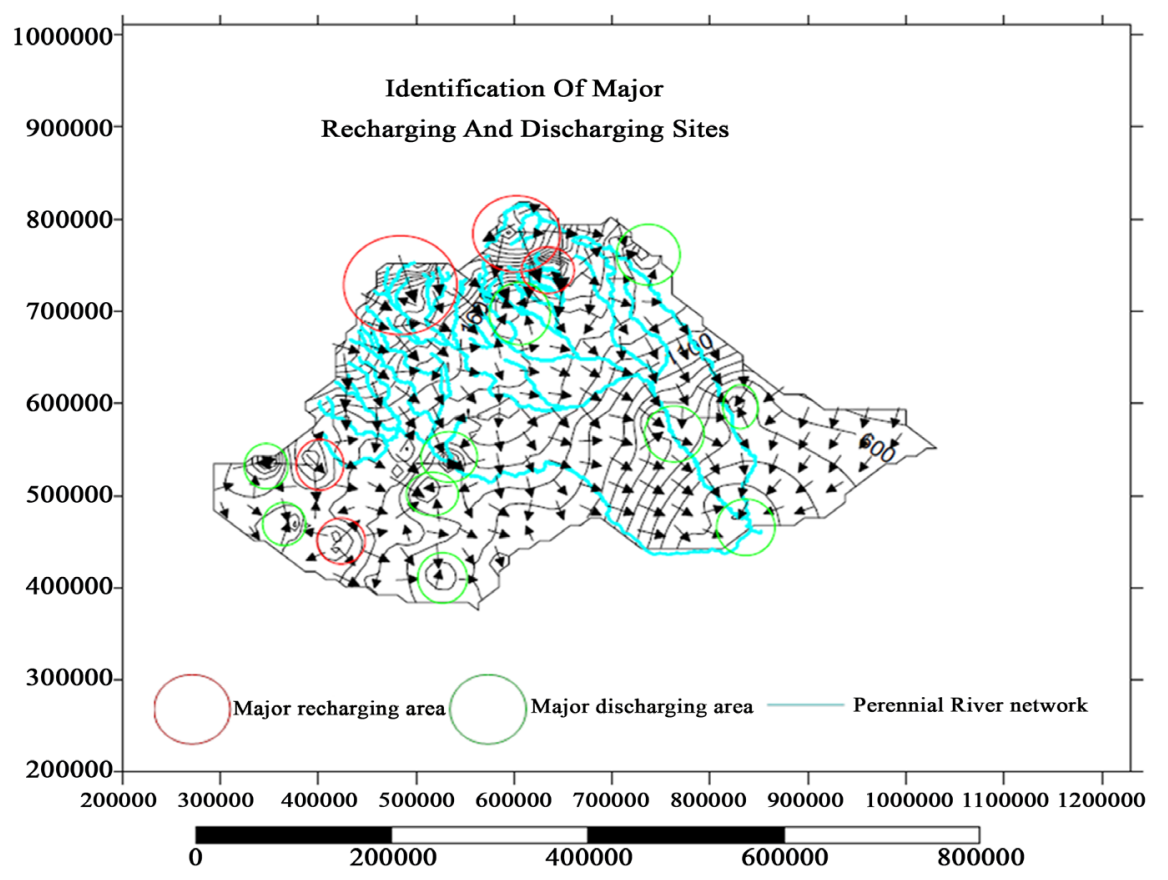

Figure 10. Identification of Recharging and discharging areas in Genale-Dawa river ba$\sin$.

management that can be used for groundwater pollution management and more. This study used finite element based three dimensional groundwater modeling program called TAGSAC to estimate the groundwater recharge. The findings of this research showed that the basin has an average recharging potential of 2.78 BCM. However, further study on estimation of extraction factor shall be done. This factor accounts for the sociological, botanical and other concerned factors to determine the safest amount of groundwater that can be extracted 
from the basin. In addition, this study also attempted to characterize the groundwater flow system of the basin by preparing hydro-geological map and flow vector field, which can be useful in selection of well field in the future.

\subsection{Recommendation}

Based on the results obtained from the study the following recommendations are forwarded;

- The identified sites of recharge area shall be protected from polluting chemicals to assure quality of the regions groundwater. Forestation of this area on the other hand can increase the available groundwater reserve by increasing the amount of infiltration and percolation; hence, it is recommended to plan and execute environmental protection projects in these regions.

- Identified discharging areas can be used as well fields after carrying out the necessary detail investigation on the site. Therefore the regional authorities can consider ground water based water supply schemes for domestic and industrial purposes.

\section{Conflicts of Interest}

The authors declare no conflicts of interest regarding the publication of this paper.

\section{References}

[1] Moges, S. (2012) Ag Water Solutions Project Case StudyAgricultural Use of Ground Water in Ethiopia: Assessment of Potential and Analysis of Economics, Policies, Constraints and Opportunities. International Water Management Institute (IWMI), Research Report.

[2] Semu (2012) Ag Water solution project, Case Study. International Water Management Institute (IWMI), Research Report.

[3] MOWR (2007) Integrated River Basin Master Plan Studies.

[4] Mohammed, M. (2010) Adaptive Neuro Fuzzy Inference System Approach for Prediction of Hydraulic Pressure Recharge. Annual Journal of Hydraulic Engineering.

[5] Sarkar, S., Toksöz, M.N. and Burns, D.R. (2002) Fluid Flow Simulation in Fractured Reservoirs. Earth Resources Laboratory, Massachusetts Institute of Technology.

[6] de Vries, J.J. and Simmers, I. (2000) Ground Water Recharge: An Overview of Processes and Challenges. Hydrogeology Journal, 10, 5-17.

[7] Healy, R.W. (2010) Estimating Groundwater Recharge. Cambridge University Press, Cambridge.

[8] Anderson, M.P. and Wosner, W.W. (1992) Applied Grounwater Modeling; Simulation of Flow and Advictive Transport. Accadamic Press, Sen Dieago, New York, Boston.

[9] Reilly, T.E. (2001) USGS Book 3, System and Boundary Conceptualization in Ground-Water Flow Simulation.

[10] Fits, C.R. (2002) Groundwater Science. Academic Press, Amsterdam, Sidney, London.

[11] Essink, G.O. (2000) Ground Water Modeling. L4018/GWMI/Utrecht University, Utrecht. 


\section{Appendix}

\begin{tabular}{|c|c|c|}
\hline No. & Code & Description of Geologic class \\
\hline \multicolumn{3}{|r|}{ Quaternary Volcanics and Sediments } \\
\hline 1 & Q & Undivided alluvium, eluvium and lacustrine sediments \\
\hline 2 & Qa & Alluial deposits: Gravel, sand silt and clay \\
\hline 3 & Qe & Eluvium: Red to reddish brown sandy soil black cotton soil calcrite, minor ferricrite, silt clay \\
\hline 4 & Qv6 & Augite-olivine-phyric basalt, scoraceous-vesicular with xenoliths of mantle nodules \\
\hline 5 & Qv5 & Pyroclastic surge deposits: Lapilli tuff \\
\hline 6 & Qv4 & Olivine-phyric-basalt \\
\hline 7 & Qv3 & Pyrocalistic surge deposits: Lapilli tuff \\
\hline 8 & Qv2 & Augite-abradorite-lapilli tuff \\
\hline 9 & Qv1 & Pyrcasitic surge deposits: Mainly bedded fall deposits scoria, rock fragments \\
\hline 10 & Qv & Scoraceous-vesicular-oilivine-phyric basalt \\
\hline \multicolumn{3}{|r|}{ Tertiary Volcanic Sucessions } \\
\hline 11 & $\mathrm{Nn}$ & Nazeret Group: Stratoid silics-ignimbites, tuffs, ash, rhyolites, trachye, minor basalt \\
\hline 12 & Ntr3 & Alkal trachyte flows \\
\hline 13 & Ntr2 & Alkali trachyte and basalt flows \\
\hline 14 & $\mathrm{Nb}$ & Bulal Basalt flows \\
\hline 15 & $\mathrm{NMv}$ & Upper basal flows \\
\hline 16 & PNtr1 & Alkali trachyte and basalt flows, rhyolitic ignimbrite, minor tuff and bassal flows \\
\hline 17 & NMt & Teltele basalt flows \\
\hline 18 & $\mathrm{PNi}$ & Ignimbrite, minore tuff and bassalt \\
\hline 19 & $\mathrm{PNb} 2$ & Ankaramite and minor divine-phyric basalt \\
\hline 20 & PNb1 & Lower flood basalts \\
\hline 21 & Tsy & Hornblende-Alkali syenite, minor hornblende-nepheline syenite \\
\hline \multicolumn{3}{|r|}{ Mesozoic Sedimentary Successions } \\
\hline 22 & $\mathrm{Ka}$ & Amba Aradam formation: Varicoloured sandstones with inter beddding \\
\hline 23 & $\mathrm{Km}$ & Mustahil formation: Limestones inerbedded with shales and marls \\
\hline 24 & Kg2 & dominantly gypsum and anhydraites with beds of limestones, shales, marl and iron carbonate rock \\
\hline 25 & Kg1 & $\begin{array}{l}\text { Korahe formation: Lower unit dominantly sandstones with bes of dolomites, limestones marl, shale, } \\
\text { gypsum and anhydrites }\end{array}$ \\
\hline 26 & $\mathrm{Jg}$ & Gabredarre formation: Micritic to microcrysaline and oolitic limestones \\
\hline 27 & Jh2 & Hamanlei formation: Micritic locally oolitic (grainstone) peletic limestones \\
\hline 28 & Jh1 & Hamanlei formation: Less fossiliferous limestones with beds of calcareous sandstone \\
\hline 29 & $\mathrm{Ja}$ & Adigrat formation: Variegated quatzos sanstones, intercalations of siltstones, shales and intrafomational conglomerates \\
\hline \multicolumn{3}{|r|}{ Precambrean-Early Paleozoic Basement Cmplexes } \\
\hline 30 & pcgt2 & Blotite and homblende granites \\
\hline 31 & pcdt & Meta-quartz diorite plutonic bodies \\
\hline
\end{tabular}




\begin{tabular}{|c|c|c|}
\hline 32 & pcgb1 & Metagabbro \\
\hline 33 & pcgd & Metagranodiorite \\
\hline 34 & pcgt1 & Biotite metagranite \\
\hline 35 & pcdt2 & Quartz metadiorite \\
\hline 36 & pcdt1 & Melka Guga diorite gneiss \\
\hline \multicolumn{3}{|r|}{ Mafic-Ultramafic-Volcano-Sedimentary Assemblages } \\
\hline 37 & pckb & Kajimiti Beds: Metasandstone and metaconglomerate \\
\hline 38 & $\operatorname{pcsc} 3$ & Metasediments: philite, metasiltstone melasandstone, micaschists, quartz-graphite-muscovite, kyanite-muscovit schists \\
\hline 39 & pcsc2 & Metavolcanics: Amhibotite and plagioclase-chlorite-actinitit schist \\
\hline 40 & $\operatorname{pcsc1}$ & Subvolcanic amphibolite \\
\hline 41 & pcum2 & Metaomblendite \\
\hline 42 & pcgb2 & Metagabbro \\
\hline 43 & pcum4 & Talc, tremolite-Chiorite-talc, chlorite, chlorite-actindite and actinolite schists \\
\hline 44 & pcum3 & Serpentinite \\
\hline 45 & pcum1 & Undeferentiated metaltramafics \\
\hline \multicolumn{3}{|r|}{ Gneissic and Migmataitic Complexes } \\
\hline 46 & pcgn11 & Quartz-graphite schist, minor marble and quartz-sericite schist \\
\hline 47 & pcgn10 & Biotite-microline-quartz and gamet-staurolite-gneises and amphibolite \\
\hline 48 & pcgn9 & Biotite-quartz-oligoiase gneiss, amphibolite and digoclase-quartz-microcline gneiss \\
\hline 49 & pcgn8 & Strongly migmatized-bioite-quartz-felspar gneiss(paragneisses) \\
\hline 50 & pcgn7 & Oligoclase-hornblende-biotite-quartz, biotite-hornblende, biotite and calcsilicate \\
\hline 51 & pcgn6 & Quartzofeldspathic gneiss, minor biotitie-feldspar-quartz gneiss and biotite granite pods \\
\hline 52 & pcgn5 & Magetite-quartzofeldspathic gneiss \\
\hline 53 & pcgn 4 & wadera mylonite and mylonitic gneiss \\
\hline 54 & pcgn3 & Hornblende-biotite-quartz-feldspar and biotite-quartz-feldspar gneisses \\
\hline 55 & pcgn 2 & Biotite-hornblende gneiss \\
\hline 56 & pcgn1 & Granulite-quartzofeldspathic gneiss \\
\hline
\end{tabular}

